\title{
Recent Intensified Winter Coldness in the Mid-High Latitudes of Eurasia and Its Relationship with Daily Extreme Low Temperature Variability
}

\author{
Chuhan Lu, Shaoqing Xie, Yujing Qin, and Jiewen Zhou \\ Key Laboratory of Meteorological Disaster, Ministry of Education, Joint International Research Laboratory of \\ Climate and Environment Change, Collaborative Innovation Center on Forecast and Evaluation of Meteorological Disasters, \\ Nanjing University of Information Science \& Technology, Nanjing 210044, China \\ Correspondence should be addressed to Chuhan Lu; luchuhan@nuist.edu.cn
}

Received 14 December 2015; Revised 11 February 2016; Accepted 14 February 2016

Academic Editor: Alex Cannon

Copyright (C) 2016 Chuhan Lu et al. This is an open access article distributed under the Creative Commons Attribution License, which permits unrestricted use, distribution, and reproduction in any medium, provided the original work is properly cited.

Observational records in recent decades show a large-scale decrease in the cold-season temperature variance in the Northern Hemisphere midlatitudes under continuous global warming. However, severe low temperature events in winter frequently occurred in midlatitude Eurasia (MEA) in the last decade. Here, we define a new coldness intensity (CI) index for the near-surface based on the amplitude of daily anomalously cold temperatures in winter to demonstrate the CI of the variability of low temperature extremes. The results show that a sign-consistent mode dominates the CI variation in MEA, with a marked intensification during the last decade via empirical orthogonal function (EOF) analysis. This leading mode is significantly related to the frequency of winter extreme events. The associated circulations are characterized by a remarkable anomalous anticyclone in Northwest Eurasia, which induced substantial cold advection in MEA. The widespread intensified CI in MEA is closely linked with strong surface anticyclones and synoptic blocking in the mid-high latitudes $\left(25^{\circ} \mathrm{E}-85^{\circ} \mathrm{E}\right)$. Coincidently, positive phase shifts of the first two leading modes of the extratropical circulation, which feature similar blocking-like anomalies in the northwestern Eurasian subarctic, jointly play an important role in the recent frequency of severe winters.

\section{Introduction}

During the past decade, cold and anomalously heavy snowfall has affected most midlatitudes of the Northern Hemisphere, including major industrialized centers, along with an overall gradual warming trend and an acceleration of Arctic seaice accumulation [1-3]. Considerable interannual variability and markedly cold winters have accompanied this unforeseen cooling trend in midlatitudes of the Northern Hemisphere [4]. One of the most impressive cold winters in recent years occurred in the midlatitudes of Eurasia in January 2008, when a freezing rain event in southern China disrupted traffic and damaged infrastructure with an economic loss of more than 100 billion Yuan $[5,6]$.

A number of studies have focused on the recent increase in midlatitude cold extremes and their attributions. Several studies have demonstrated some possible connections between Arctic amplification, midlatitude weather, and climate extremes [7-9]; however, the statistical robustness and physical mechanisms of the connections are still unclear [10-12]. The Arctic sea-ice losses and warm North Atlantic sea surface temperature (SST) may both play important roles in the air temperature variability over the East Asia monsoon region during cold seasons $[3,13,14]$ by linking the change in the Arctic Oscillation (AO)/North Atlantic Oscillation (NAO), Atlantic Multidecadal Oscillation (AMO) [15], and the Siberian High [16]. Persistent weather systems may also contribute to large-scale cold extremes [5, 17-19]. Zhang et al. [20] reported that the intensified synoptic anticyclone activity after the early 2000 s had a prominent impact on the increased frequency of cold weather events. 
The subseasonal variance in the daily temperature can be used to quantify the overall seasonal high-frequency temperature fluctuation $[21,22]$. The increased cold-season temperature variance suggests that cold outbreaks or warm events occur more frequently. However, in contrast to the recent increased extreme cold weather in the midlatitudes of Eurasia, decreases in the subseasonal all-longitude zonal mean temperature variability have been detected over the past few decades [23]. Schneider et al. [24] argued that such inconsistency resulted from a warmer mean climate, which entails changes in the frequency with which fixed temperature thresholds are exceeded. The research question is as follows: how can the integrated intensity of the recent extreme cold events during the cold season be quantified?

Here, we defined a new objective index to quantify the intensity of winter coldness and focused on its contribution to the recent increased large-scale extreme cold events in the midlatitudes of Eurasia (MEA). The associated circulation patterns and their relationship with synoptic weather systems will be discussed to explain the change in the recent intense cold events in MEA.

\section{Data and Methodology}

2.1. Data. This study uses the daily data from the ECMWF ERA-Interim reanalysis from January 1, 1979, through December 31, 2013 [25]. We use a full T255 $(512 \times 256)$ Gaussian grid, which has an approximate global horizontal resolution of $0.7^{\circ} \times 0.7^{\circ}$. And the gridded daily minimum and maximum surface air temperature $\left(T_{\min }\right.$ and $\left.T_{\max }\right)$ are also from the ERA-Interim associated forecast field. Furthermore, we use $T_{\min }$ and $T_{\max }$ data at the 1331 Eurasian meteorological stations from the daily global historical climatology network from 1972 to 2012 (GHCN-DAILY, https://gis.ncdc.noaa.gov/ geoportal/catalog/search/resource/details.page?id=gov.noaa .ncdc:C00861). Although there are more temperature stations in the Eurasian mid-high latitudes, we only chose 1331 stations having sufficiently long record from 1973 to 2012. Considering the sparsity of stations over northern China and Mongolia, we added 215 stations over these regions from the daily Chinese surface climate dataset (V3) and baseline meteorological data in Siberia (V5). The mean monthly indices of the AO are taken from http://www.cpc.ncep.noaa.gov/products/precip/ CWlink/daily_ao_index/ao.shtml. In this study, winter means were constructed by averaging the data for December, January, and February (DJF), which resulted in 35 winters (1979-2013).

2.2. Definition of Intensity of Winter Coldness. Percentilebased indices that consider the occurrence of cold spell days and cold days are widely applied to study changes in daily extreme cold events. However, the frequency of extremes depends on the choice of the percentile value (e.g., 5th and 10 th for cold events); the indices may not reflect the seasonal integrated intensity of cold events well because they also depend on the amplitude and persistence of events. On the other hand, the traditional subseasonal temperature variance would underestimate the seasonal intensity of coldness if a persistent cold condition dominates the cold season despite an increase of extreme cold events. Moreover, the warm events would also induce an amplification of the values of variance if we focus on the cold anomalies and associated cold extremes. Therefore, we define a new coldness intensity (CI) in winter as

$$
\begin{aligned}
& \mathrm{CI}=\frac{1}{90} \sum_{i=1}^{90}\left(\frac{T_{i}^{\prime}}{\sigma_{i}}\right)^{2}, \\
& T_{i}^{\prime}= \begin{cases}T_{i}-\bar{T}_{c} & T_{i}-\bar{T}_{c}<0 \\
0 & T_{i}-\bar{T}_{c} \geq 0 .\end{cases}
\end{aligned}
$$

Here, $T_{i}$ is the daily $925 \mathrm{hPa}$ temperature from December 1st in the preceding year to February 28th in the current year $(90$ days for DJF). $T_{i}^{\prime}$ is a cold anomaly relative to the climatology $\left(\bar{T}_{c}\right)$ of 90-day mean of $T_{i}$ from 1979 to 2013 when $T_{i}-\bar{T}_{c}<0$. When $T_{i}$ is relative warm $\left(T_{i}-\bar{T}_{c} \geq 0\right)$, the value of $T_{i}^{\prime}$ becomes zero so that the anomalous warmth is excluded. To homogenize the fluctuations among different locations, the values were divided by the standard deviation $\left(\sigma_{i}\right)$ at each grid point, that is, the multiyear standard deviation at a grid point on the $i$ th day. Because the $T_{i}^{\prime}$ represents a cold deviation from climatology (1979-2013), the value of its intraseasonal variability or CI measures a seasonal integrated magnitude of cold anomalies in winter. Accordingly, the standardized value of CI differs from its corresponding standardized subseasonal fluctuation, especially in a persistent cold (warm) winter, which may include more frequent cold (warm) extremes.

\section{Result}

3.1. Recent Intensified Winter Coldness. We used the 10th percentile of the daily maximum (minimum) surface air temperature (SAT) over 1979-2013 based on ERA-Interim to obtain cold day (night) events. The zonal mean $\left(0^{\circ}-180^{\circ} \mathrm{E}\right)$ occurrence of extreme low temperatures shows a clear interdecadal fluctuation in the midlatitudes of Eurasia (MEA) since 1979 (Figures 1(a) and 1(b)). The low temperature events at $30^{\circ} \mathrm{N}-60^{\circ} \mathrm{N}$ exhibited a notable decline in the 1990 s and the early 2000s, which corresponded to the gradual warming in the global surface temperature. However, a significant increase in cold days and cold nights emerged after the mid2000 s in accordance with the recent severe winters over Eurasia (04/05, 05/06, 07/08, 09/10, 10/11, 11/12, and 12/13). The mean frequencies of cold days (nights) in 1979-1989, 1990-2004, and 2005-2012 are 13.4 (14.7) dy, 11.7 (12.0) dy, and 15.7 (15.2) dy, respectively. Thus, stronger cooling conditions occurred over Eurasia in recent years compared with the 1980s.

After the mid-2000s, the subseasonal temperature variance at $925 \mathrm{hPa}$ displayed greatly contrasting anomalies between $30^{\circ} \mathrm{N}-45^{\circ} \mathrm{N}$ and $45^{\circ} \mathrm{N}-60^{\circ} \mathrm{N}$ (Figure $1(\mathrm{c})$ ). Note that the variance is also divided by $\sigma_{i}$ to homogenize the fluctuations among different locations. The linear trend for 19962013 is 1.1 per decade at $30^{\circ} \mathrm{N}-45^{\circ} \mathrm{N}$ (exceeding the 0.1 significance). The intensified subseasonal fluctuation indicates more unstable weather changes during the cold seasons; for example, more frequent cold air outbreaks may occur. In contrast, a decrease of -1.0 per decade emerged at $45^{\circ} \mathrm{N}-60^{\circ} \mathrm{N}$, 


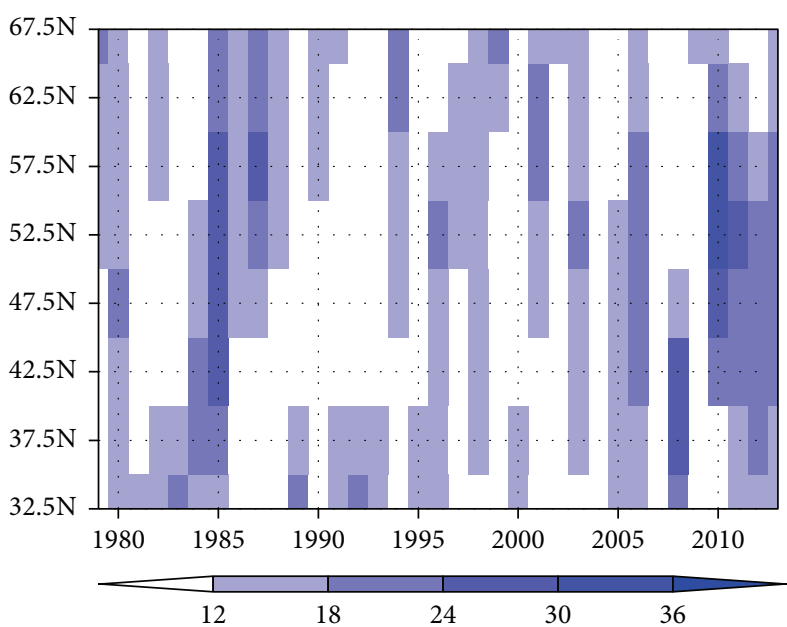

(a) Cold days

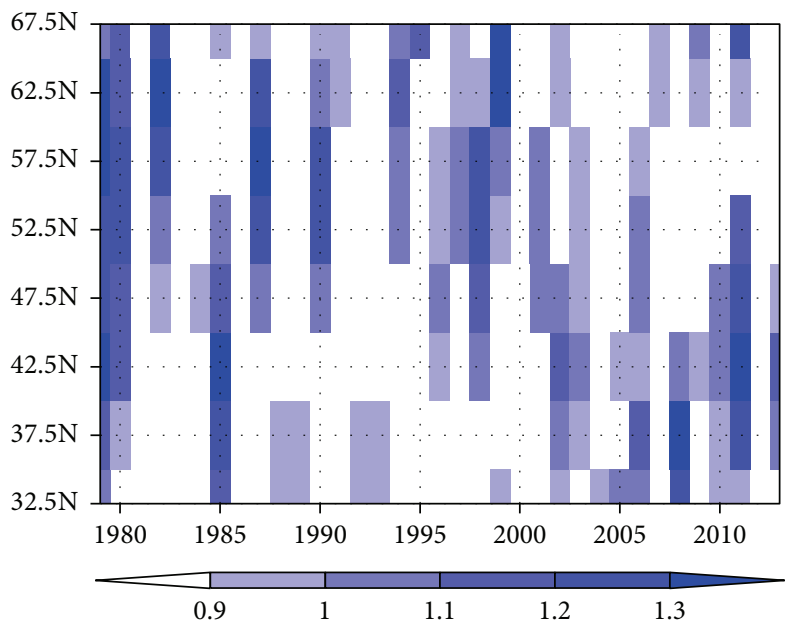

(c) Standard variance

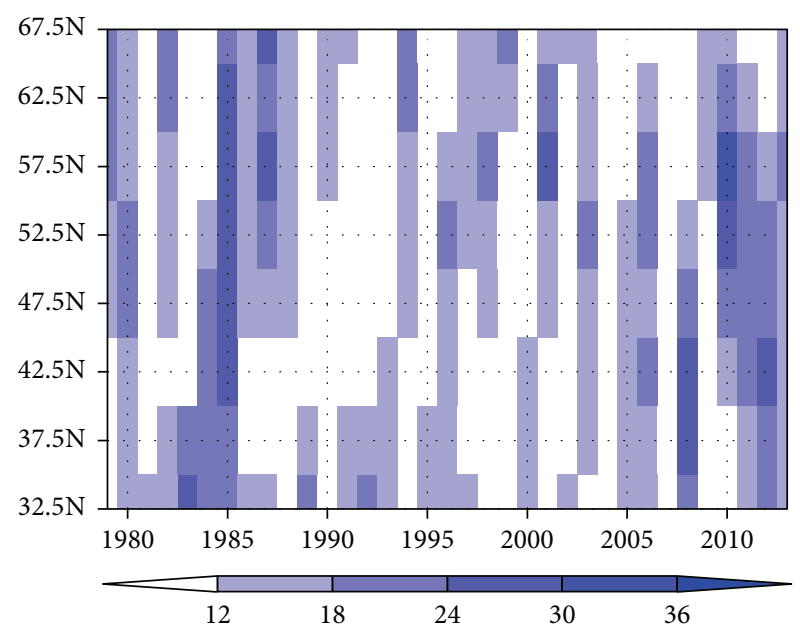

(b) Cold nights

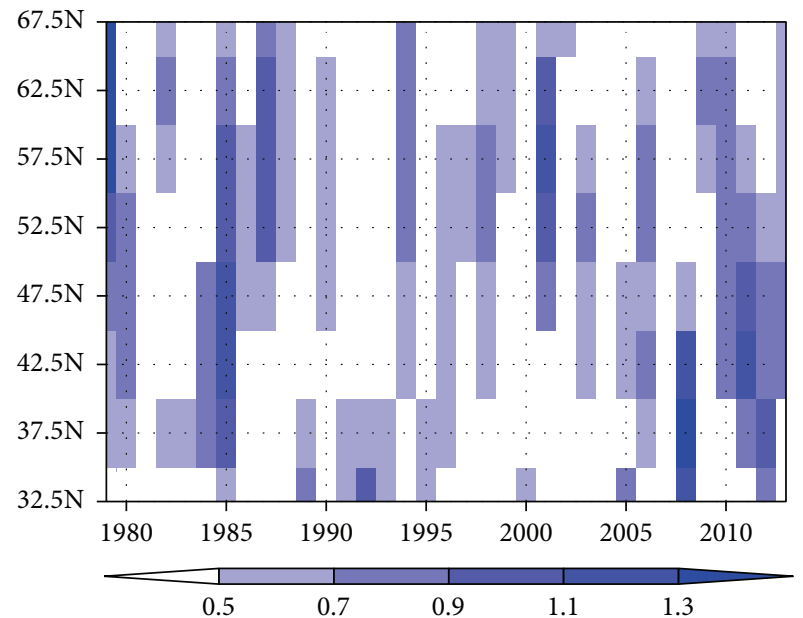

(d) $\mathrm{CI}$

FIGURE 1: Changing extreme cold events, $925 \mathrm{hPa}$ temperature variability, and CI. Zonal mean $\left(0^{\circ}-180^{\circ} \mathrm{E}\right)$ winter cold days ((a) unit: days), cold nights ((b) unit: days), intraseasonal variance (c), and CI (d) during 1979-2013. The values are calculated at each grid point before area averaging for $5^{\circ}$ latitude bands from $30^{\circ} \mathrm{N}$ to $70^{\circ} \mathrm{N}$. The 1979-2013 mean is used as the climatological value in (d). The units for (a) and (b) are days.

which is inconsistent with the low temperature extremes in Figures 1(a) and 1(b). However, the decrease trend is not significant. Therefore, the overall linear trend at $30^{\circ} \mathrm{N}-60^{\circ} \mathrm{N}$ displays a weak increase ( 0.05 per decade). This indicates a reduction of the synoptic temperature variance near the surface during the cold season, which is consistent with the all-longitude zonal mean results of Screen [23].

As shown in Figure 1(d), the variation in the CI greatly resembles the change in the frequency of cold days and cold nights. A remarkably strong CI is observed over $30^{\circ} \mathrm{N}-45^{\circ} \mathrm{N}$ and $45^{\circ} \mathrm{N}-60^{\circ} \mathrm{N}$ after the mid-2000s, which is coincident with more frequent low temperature events. Considering that colder conditions favor cool weather events, the increase in the synoptic negative temperature variability physically indicates a better chance of low temperature extremes, and vice versa. The inconsistency between intraseasonal variance and CI implies that more persistent cold events, as well as more frequent percentile-based low temperature extremes, may have occurred in recent years despite the possibly less frequent cold outbreaks in the context of global warming.

To explicitly analyze the spatial-temporal characteristics of the winter CI in MEA, an EOF analysis is applied to the winter CI over $0^{\circ}-180^{\circ} \mathrm{E}$ and $30^{\circ}-55^{\circ} \mathrm{N}$ during $1979-2013$. The variance contribution rates of the first two modes are $32 \%$ and $23 \%$, which can be well discriminated according to the criterion proposed by North et al. [26]. The spatial distribution of the leading mode (EOF1) of the CI and its corresponding time series (PC1) are shown in Figure 2. As depicted in Figure 2(a), the EOF1 mode shows a pattern of consistent positive CI departures in MEA, indicating consistent intensifying or weakening coldness in winter. The areas with high values are mainly located west of $50^{\circ} \mathrm{E}$, with the largest variability around northwestern China. PC1 exhibits clear interdecadal variation superimposed on large 


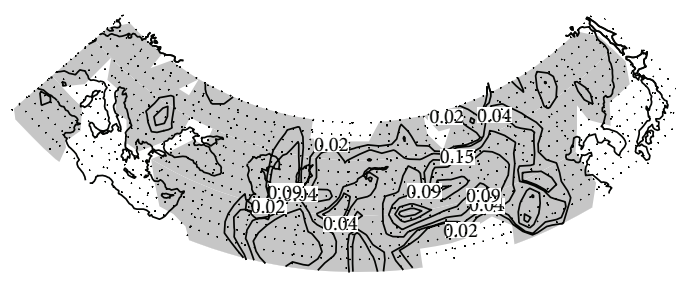

(a)

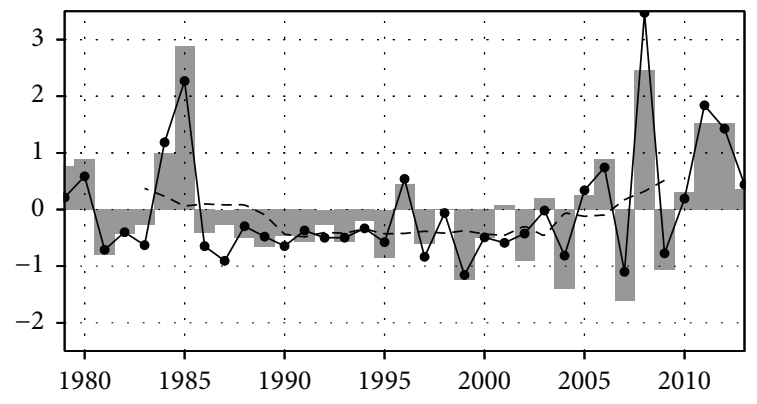

(b)

Figure 2: (a) EOF1 mode of the CI anomalies at 30-55 $\mathrm{N}$ in Eurasia. (b) Standardized time series of PC1 (dotted solid line), the regional (30$55^{\circ} \mathrm{N}, 0-180^{\circ} \mathrm{E}$ ) average CI (ECI, bar), and its corresponding 9 -yr running mean (dashed line). The areas with positive values are shaded in (a).

interannual variability in recent decade (Figure 2(b)). In particular, the positive phase occurs during the early and mid-1980s, followed by dominantly negative values from the late 1980 s to the beginning of the 21 st century; then, a positive phase with sharply higher values occurred. Considering the spatial sign-consistency of EOF1, we calculated a regional average CI over MEA and defined it as ECI for simplicity (gray bar in Figure 2(b)). Clearly, the variations between PC1 and ECI as a function of time are highly coincident, whereof ECI is in correlation with PC1 at a value of 0.94 . Thus, both $\mathrm{PCl}$ and $\mathrm{ECI}$ indicate the variability in the subseasonal coldness fluctuation in MEA. EOF2 is characterized by a north-south opposing variation, with positive values mainly located south of $40^{\circ} \mathrm{N}$ (figure not shown). However, the correlation coefficient between PC2 and ECI decreases to -0.14 . Therefore, the relationship between the EOF2 variability and widespread cooling in MEA is not as close as that between EOF1 and ECI. Thereafter we focus on EOF1 and ECI.

To show the representativeness of ECI to CI in MEA, we further correlated the time series of ECI with the time series of CI at each grid point. A significant correlation between ECI and coldness intensity is observed in MEA and in large areas of China except the Tibetan Plateau (Figure 3(a)). In particular, the high positive correlation, with values above 0.6 (exceeding the $0.01 t$-test significance), are mainly located in Central Europe, Central Siberia, and Northwest China. This is consistent with the large areas of EOF1 variability. Furthermore, significant positive correlations also emerge over East China, the Korean Peninsula, and North Japan. The overwhelming significant positive correlations suggest generally homogeneous large-scale winter $\mathrm{CI}$ variability over MEA during the cold season, as indicated by ECI.

As shown in Figures 3(b) and 3(c), the correlation between the ECI and the frequency of cold days and cold nights based on gridded $T_{\min }$ and $T_{\max }$ from ERA-Interim is generally identical to that between the ECI and CI (Figure 3(a)), which exhibits a dominantly large positive correlation at $30^{\circ} \mathrm{N}-60^{\circ} \mathrm{N}$, with a westward shift centered at Kazakhstan. Significant areas also spread to the western Bering Sea and west of the Ural Mountains. Note that we used 1979-2013 as a reference period in defining cold events; the results may be influenced by the warmer mean temperature in the context of the warming climate [24]. To examine the robustness of the relationship between the ECI and temperature extremes, we redefined the cold days and cold nights as days for which the stations $T_{\min }$ and $T_{\max }$ were less than the corresponding 10th percentile value (1973-1992) following Zhang et al. [27]. As documented in Figures 4(a) and 4(b), a widespread significant positive correlation occurs despite the data gap in Mongolia. Although the significance level between the ECI and the frequency of cold nights is relatively lower in East China, the correlations obtained by the reanalysis data and station data display a highly consistent geographical distribution. Therefore, the coincident strong correlations of both the coldness intensity and low temperature extremes with the ECI indicate that the recent frequent low temperature extremes can be well manifested by the intense coldness in the past few years.

3.2. Associated Atmospheric Circulation Anomalies. The change in the local SAT is expected to be predominantly generated by the horizontal advection of air masses from warmer or colder regions. The components of zonal $(-u(\partial T / \partial x))$ and meridional $(-v(\partial T / \partial y))$ temperature advection and their sum $(-u(\partial T / \partial x)-v(\partial T / \partial y))$ are calculated by the daily $925 \mathrm{hPa}$ temperature and horizontal winds, which include both the stationary and nonlinear transient wave contributions. Both the zonal advection and meridional advection present a physical consistency with the change in the $\mathrm{CI}$ and the frequency of low temperature extremes at MEA (Figures 5(a) and 5(b)). In general, the amplitudes of anomalous zonal and meridional components are comparable. The intense coldness in the past few years is physically linked with a remarkably cold advection due to both $-u(\partial T / \partial x)$ and $-v(\partial T / \partial y)$ components. A significant weakening of westerlies in MEA during the recent decade weakens warm zonal advection from the west part of Eurasian continent. Also, the decreased westerlies favor persistence and further intensification of surface anticyclone systems [20]. Therefore, the weak westerlies may play a physically important role in the recent decade of $-u(\partial T / \partial x)$. For $-v(\partial T / \partial y)$ component, significant intensification northerlies are shown in mid and northern Siberia (Figure 6(a)) and the cold advection because northerly becomes more efficient 


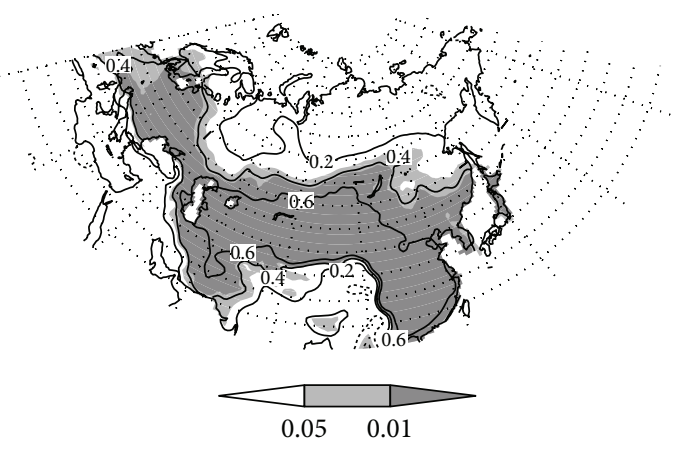

(a) $\mathrm{CI}$

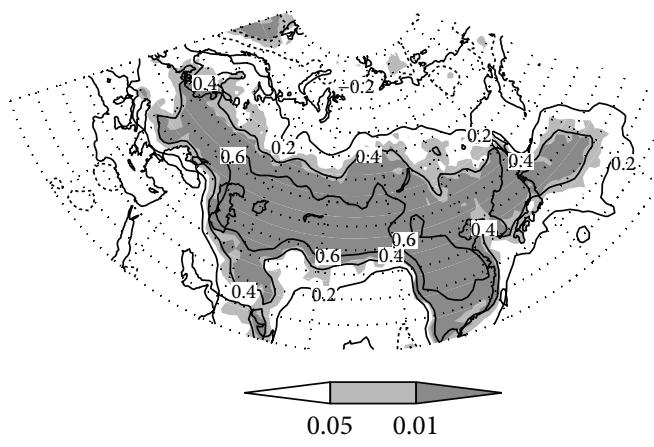

(b) Cold days

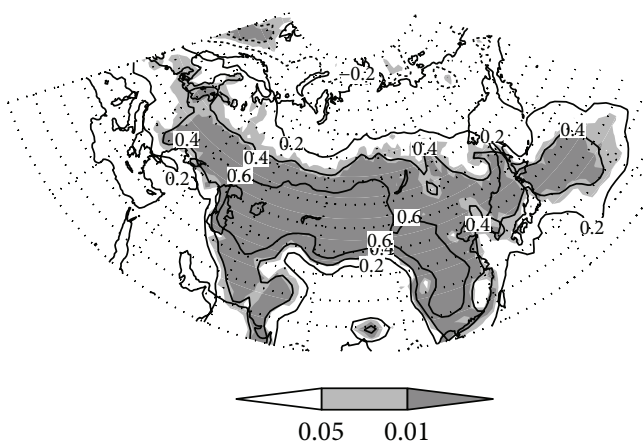

(c) Cold nights

FIGURE 3: Correlation coefficients between ECI and the coldness intensity (CI) (a) and frequency of station-based cold days (b) and cold nights (c). The shading indicates areas with significant two-tailed Student's $t$-test exceeding 0.05 and 0.01 .

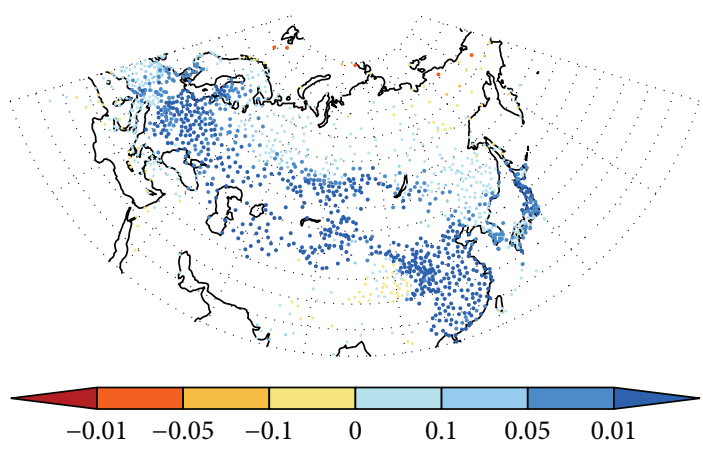

(a) Cold days

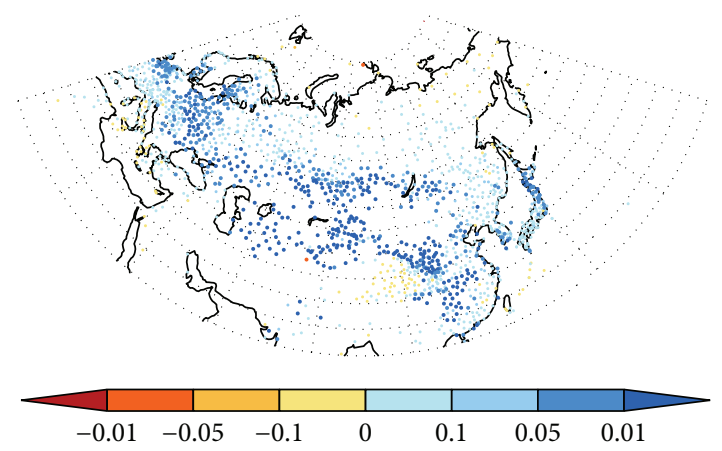

(b) Cold nights

FIGURE 4: Statistical significance of correlation coefficients between the ECI and the occurrence of station cold days (a) and cold nights (b). Here, we also used the 10th percentile threshold but substituted a stationary climatology for 1973-1992 following Zhang et al. [27]. The values of the colored bars represent the significance of the two-tailed Student's $t$-test at each station (dot); the positive (negative) sign denotes a positive (negative) correlation.

despite a possible decrease of meridional temperature gradient from the recent arctic amplification. Therefore, the recent cold advection by both $-u(\partial T / \partial x)$ and $-v(\partial T / \partial y)$ components plays an important role in the change in the horizontal temperature advection (Figure 5(c)) and winter coldness variation.

To investigate the atmospheric circulation anomalies associated with the change in the temperature advection and $\mathrm{CI}$, a composite difference in the sea-level pressure
(SLP) and horizontal wind at $925 \mathrm{hPa}$ between the high and low ECI years is shown in Figure 6(a). Note that all of the selected high/low ECI years are greater (less) than $+(-)$ the 0.5 standard deviation (SD) from the time series mean. In particular, we identified 13 low years and 10 high years, including 5 high years that occurred after the 05/06 winter. This highlights the notable intensification of coldness in MEA in recent years. Significant positive SLP differences are visible over the northwestern Eurasian subarctic (NWEAS), 


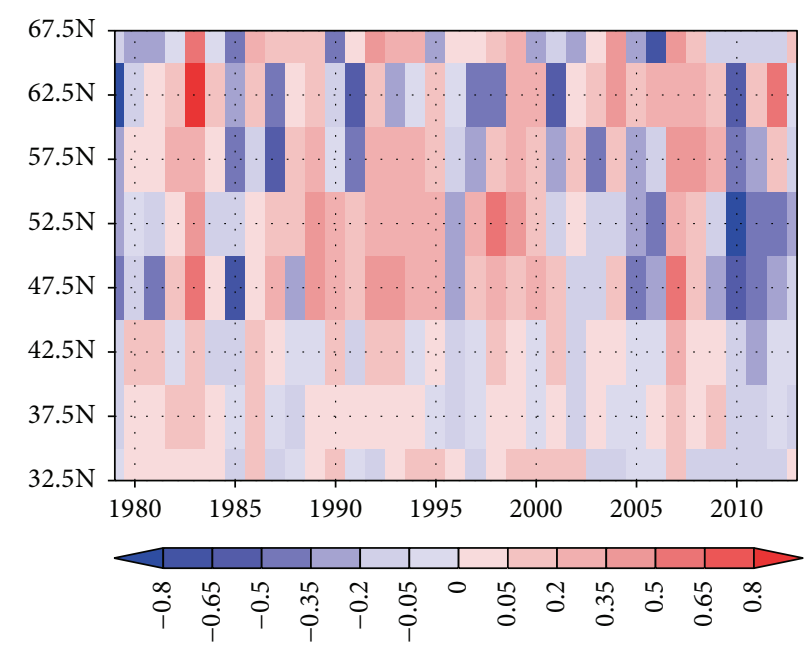

(a) Zonal Tadv

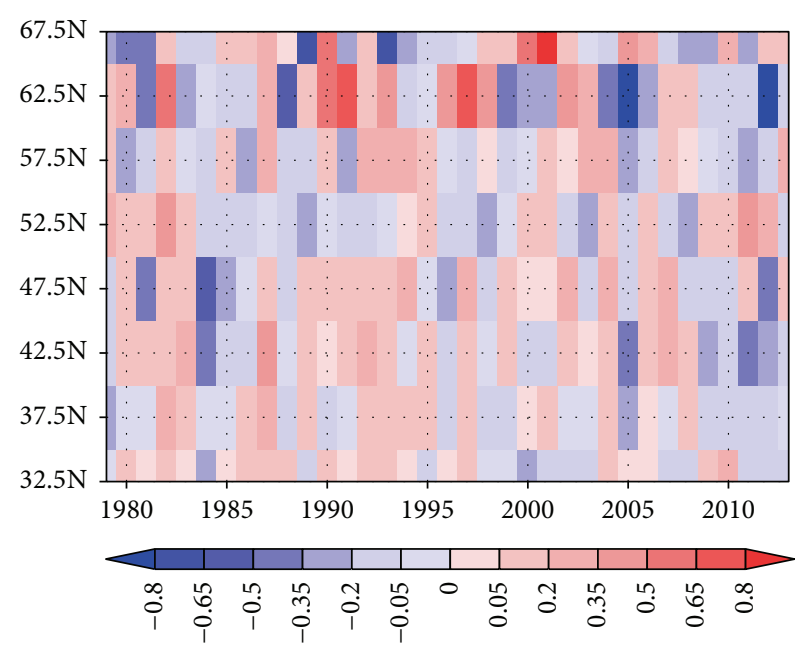

(b) Meridional Tadv

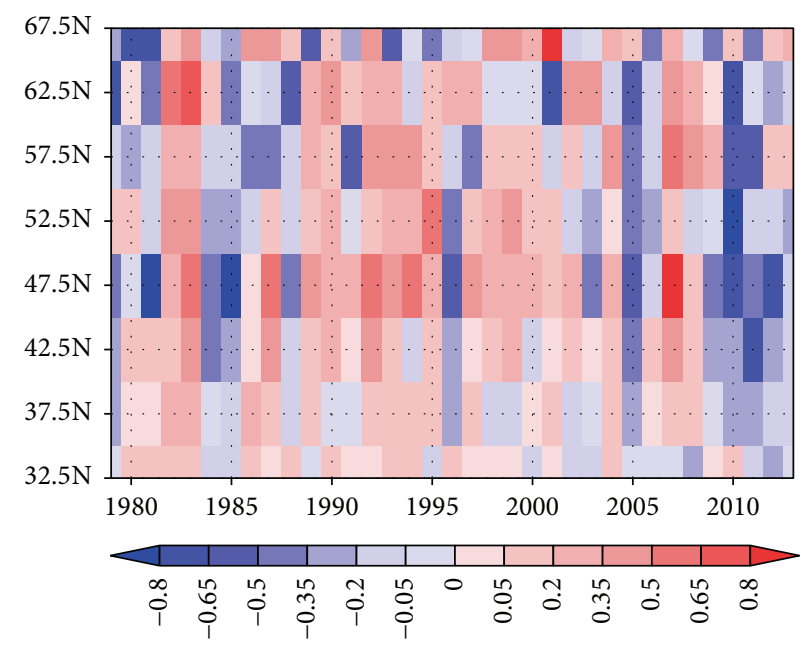

(c) Total Tadv

FIGURE 5: Changing zonal mean zonal ((a), unit: $\mathrm{K} *$ day $\left.^{-1}\right)$, meridional ((b), unit: $\mathrm{K} *$ day $\left.^{-1}\right)$, and total ((c), unit: $\mathrm{K} *$ day $\left.^{-1}\right)$ temperature advection anomalies at the $925 \mathrm{hPa}$ level (1979-2013). Values are calculated at each grid point before area averaging and are calculated for $5^{\circ}$ latitude bands.

with a maximum centered around Scandinavia. Anticyclonic near-surface wind differences are consistently apparent over the anticyclonic SLP anomalies. As expected, cold zonal advection differences are observed over most of Europe, indicating weakening zonal warm and moisture flow from the North Atlantic (Figure 6(b)). Significant cold meridional advection is shown over Siberia (Figure 6(c)). This reflects the anomalous northerlies west of the Ural Mountains, which bring cold air masses from the high latitudes. Cold meridional advection is also apparent along the coastal area of East Asia, suggesting an associated intensified East Asian winter monsoon. Accordingly, the total horizontal temperature advection shows a dominant widespread cooling effect in MEA during the high ECI years (Figure 6(d)). Consequently, the anticyclonic SLP anomalies over NWEAS associated with midlatitudinal cold advection drove the recent intensified winter coldness and increased the low temperature extremes.
3.3. Active Eurasian Anticyclone and Blocking Activity. Dramatically intensified or unusually persistent weather systems are usually linked with regional extreme cold events $[18,19]$. For example, the passing or abrupt intensification of a surface cold-core high could directly cause cold surges in the winter [28]. To assess the link between the activity of synoptic weather systems and the change in the ECI, we introduced an anticyclone intensity index (ACI) over Eurasia $\left(0^{\circ}-110^{\circ} \mathrm{E}\right.$, $40^{\circ}-75^{\circ} \mathrm{N}$ ) from Zhang et al. [20], which is defined by the integration of the central 6-hourly SLP anomalies of every synoptic anticyclone during winter (DJF mean).

The association of surface anticyclonic activity with the occurrence of severe winters over Eurasia was examined by a scatter plot of the ECI and ACI scores (Figure 7). There is a significant relationship between these two indices $(0.7$, with significance exceeding 0.01 ). More interestingly, $88 \%$ of the low temperature winters $(\mathrm{ECI}>0.5 \mathrm{SD})$, including 


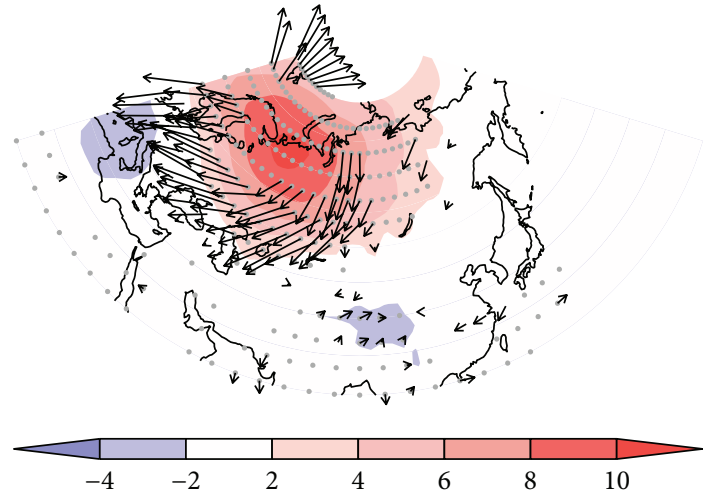

(a) SLP and UV925

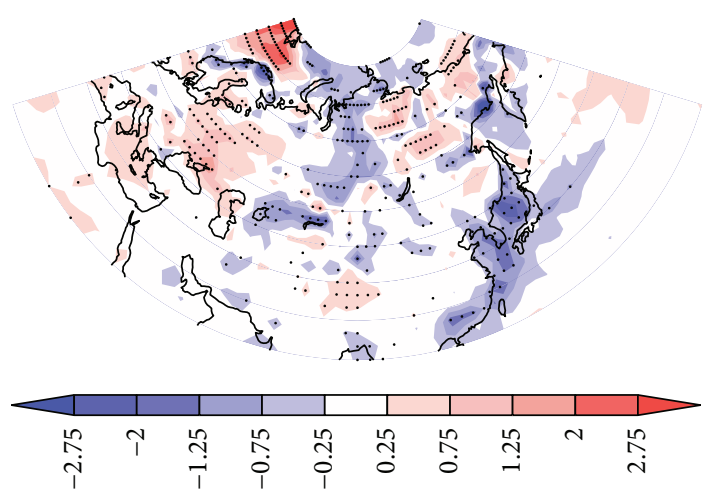

(c) Meridional Tadv

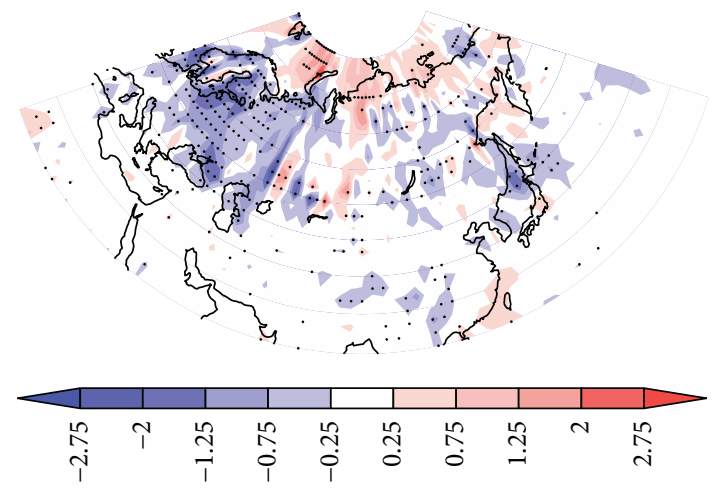

(b) Zonal Tadv

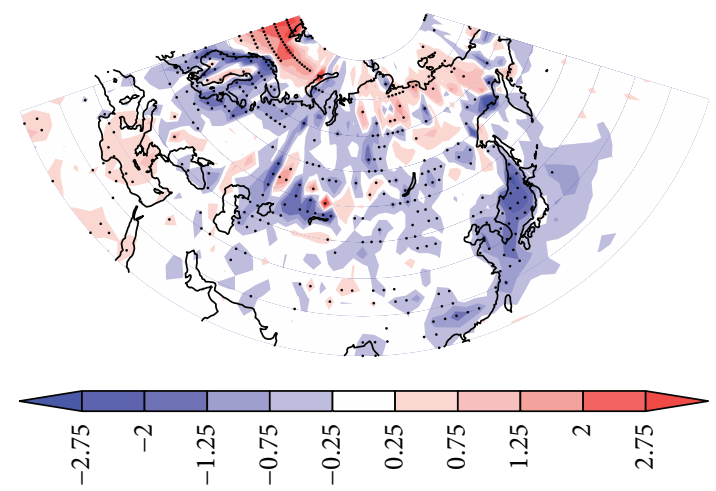

(d) Total Tadv

FIGURE 6: Composite difference between high and low ECI years ( \pm 0.5 SD) from 1979 to 2013 for the SLP (shaded) and 925 hPa wind field (vector) in ((a) the units are $\mathrm{hPa}$ for SLP $\mathrm{m} \cdot \mathrm{s}^{-1}$ for $925 \mathrm{hPa}$ wind) the zonal temperature advection ((b) unit: $\mathrm{K} *$ day $\left.{ }^{-1}\right)$, the meridional temperature advection $\left((\mathrm{c})\right.$ unit: $\left.\mathrm{K} * \mathrm{day}^{-1}\right)$, and the total horizontal temperature advection ((d) unit: $\left.\mathrm{K} * \mathrm{day}^{-1}\right)$. The dotted areas and wind vectors indicate a significant difference that exceeds 0.05 for the two-tailed Student's $t$-test.

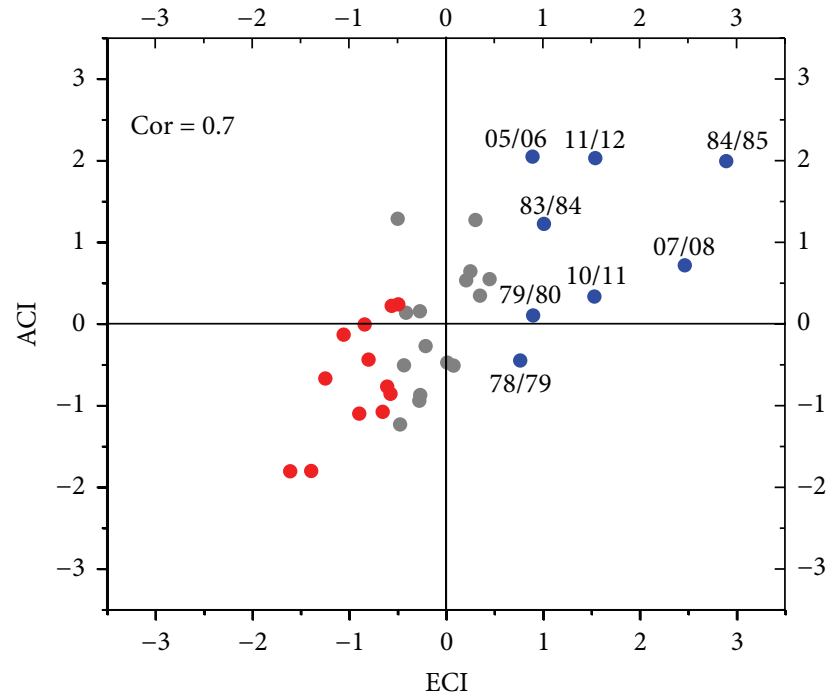

FIgURE 7: Scatter plot of the ECI and ACI for reanalysis. The blue and red marks indicate high and low ECI years $( \pm 0.5 \mathrm{SD})$, respectively; the grey marks indicate the ECI that were neither high nor low years.
4 severe winters after 2005, coincided with positive ACIs, which denote an intensified surface anticyclone over Eurasia. This indicates that the synoptic anticyclonic activity and its possible cold air outbreaks may be physically linked with the recent Eurasian cold winters.

To compare broad atmospheric circulation patterns, we examined the difference map of the SLP and $500 \mathrm{hPa}$ geopotential height (Z500) by subtracting the composites of high ACIs from those of low ACIs (Figure 8(a)). An anticyclonic SLP anomaly, together with a similar blocking-like Z500 center, is clearly seen in NWEAS. This is identical to the above composite SLP pattern by the high-low ECI with a slightly southward shifted maximum center. The significant SLP differences associated with ACIs suggest intensified surface anticyclonic activity closely connected with the stationary large-scale atmospheric circulation pattern. In conjunction with the intensified anticyclones, cold conditions were widespread across much of MEA; negative temperature differences extending eastward/southeastward from northwestern Europe to eastern China range from $-1^{\circ} \mathrm{C}$ to $-5^{\circ} \mathrm{C}$ (Figure $8(\mathrm{~b})$ ), which favors the increase in extreme cold events. We also defined the frequency of blocking 


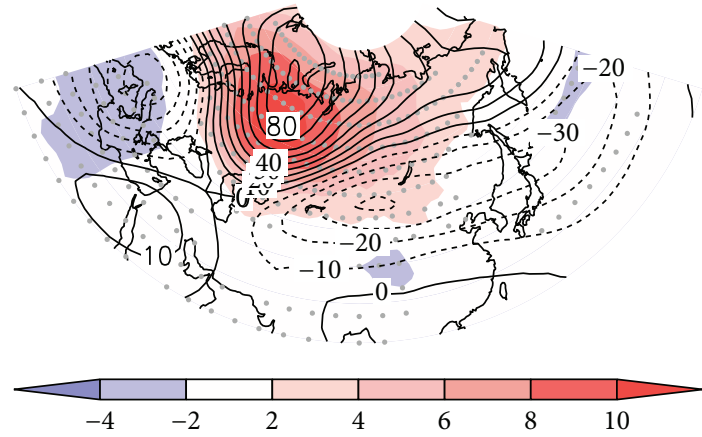

(a) SLP and Z500

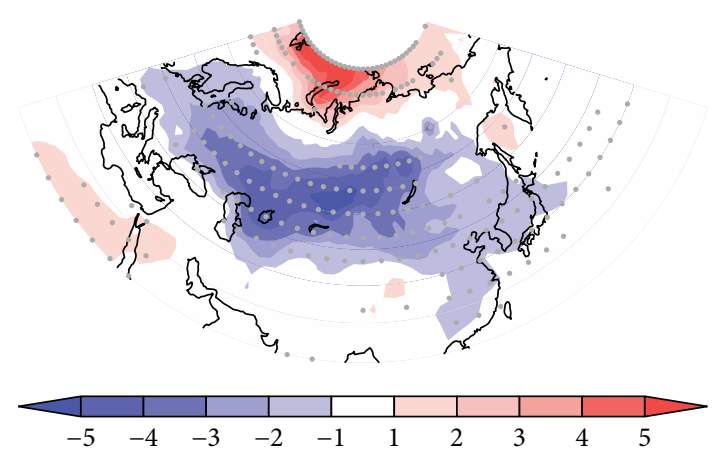

(b) SAT

FIgURE 8: Same as Figure 6 but for SLP and Z500 in ((a) the units are hPa for SLP, gpm for Z500) and SAT in ((b) unit: K) between high and low ACI years $( \pm 0.5 \mathrm{SD})$. The dotted areas indicate significant difference exceeding 0.05 for the two-tailed Student's $t$-test.

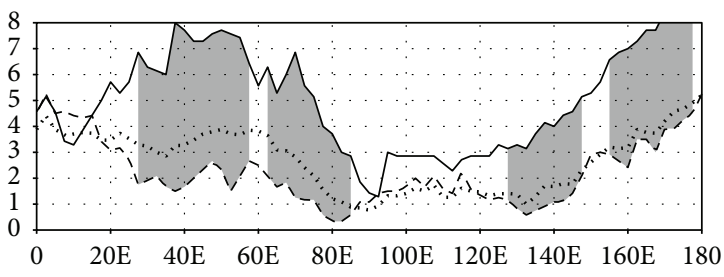

(a) ECI

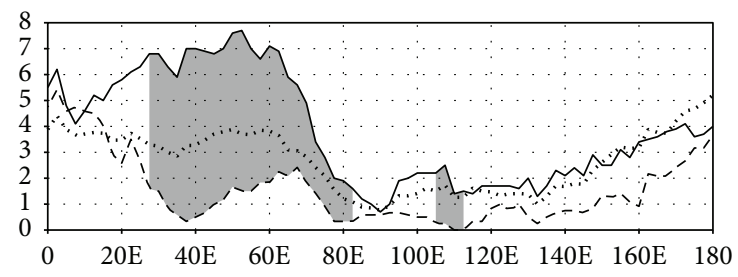

(b) ACI

FIGURE 9: Composites of winter blocking frequency associated with high-low ECI years ((a) unit: days) and high-low ACI years ((b) unit: days). The solid curve (long dashed curve) denotes composites for the high (low) index years, and the dotted curve denotes the climatological values during 1979-2013. The shaded area indicates longitudes where the difference between composites exceeds the 0.1 significance.

events over Eurasia along $30^{\circ} \mathrm{E}-85^{\circ} \mathrm{E}$ based on an objective blocking-detection method by Charney et al. [29]. Both the amplified ECI and ACI are accompanied by more frequent blocking events (Figures 9(a) and 9(b)), suggesting barotropic interactions between the surface anticyclone and upper-level blocking high connected with the development of a long planetary wave. This is consistent with previous studies, indicating the important role of synoptic weather systems in the mid-lower troposphere in explaining the extreme cold events over MEA $[9,20]$.

3.4. Changes in the Extratropical Leading Mode. Previous studies reported that the $\mathrm{AO} / \mathrm{NAO}$ significantly affects extreme weather events, such as cold air outbreaks, frozen precipitation, and strong wind events over large areas of the Northern Hemisphere $[16,21,30]$. To examine the extent of extreme cold events associated with the AO, we conducted an EOF analysis on the DJF-mean area-weighted $1000 \mathrm{hPa}$ geopotential height (Z1000) anomalies (1979-2013) north of $20^{\circ} \mathrm{N}$. The variance contribution rates of the first two modes are $29.8 \%$ and $20.9 \%$, which can also be well discriminated according to the criterion proposed by North et al. [26].

The spatial pattern of the leading mode (EOF1) of Z1000 resembles the negative-phased monthly AO (Figure 10(a)). The correlation of its corresponding time series (ZPC1) with ECI is significantly different from zero (Table 1). These results suggest that the positive phase of the EOF1 is associated with intensified cold conditions in MEA arising from the positive
TABLE 1: Correlation coefficients between all the indices studied. Note that the bold (asterisks) numbers and asterisks indicate significant difference exceeding 0.05 (0.01) for the two-tailed Student's $t$-test.

\begin{tabular}{ccccc}
\hline & AO & ZPC1 & ZPC2 & ZPC1 + ZPC2 \\
\hline ECI & $\mathbf{- 0 . 4 5}$ & $\mathbf{0 . 4 1}$ & $\mathbf{0 . 3 8}$ & $\mathbf{0 . 5 5}^{*}$ \\
\hline
\end{tabular}

Z1000 anomalies around the Arctic Ocean and its coastal areas in the Eurasia sector. Interestingly, compared with the traditional monthly data constructed AO (http://www.cpc .ncep.noaa.gov/products/precip/CWlink/daily_ao_index/ao .shtml), the Arctic center in EOF1 (individual seasonal AO) shows a clear northeastward shift from north of Iceland to the Barents Sea, together with a positive shift of the ZPC1 (Figure $10(\mathrm{~d})$ ). This indicates a spatially deformed extratropical atmospheric circulation pattern in the Northern Hemisphere during the past decade, which is consistent with the rapid changes in the Arctic climate system [1].

As shown in Figure 10(b), the second mode (EOF2) also exhibits positive Z1000 anomalies around the Barents Sea, with a weaker Aleutian low and a weak negative Atlantic center. The corresponding time series (ZPC2) shows high values since the mid-2000s (Figure 10(e)). The correlation coefficient between ZPC2 and ECI is 0.38 (passing the 0.05 significance $t$-test), indicating a close linkage between EOF2 and the intensity of midlatitudinal Eurasia cold events. 


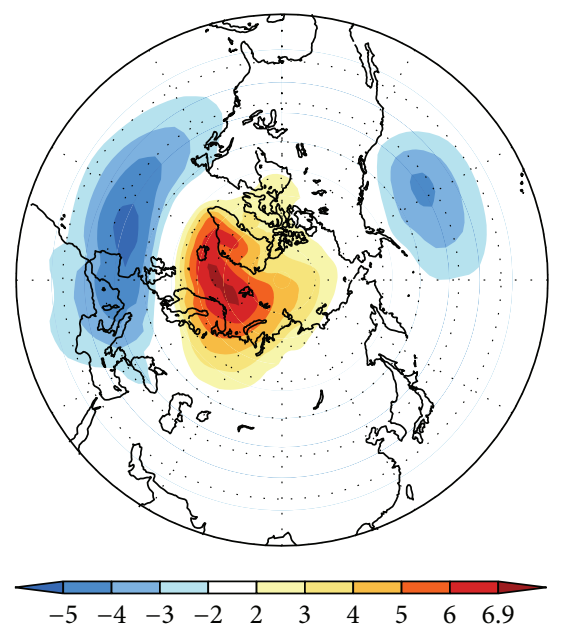

(a)

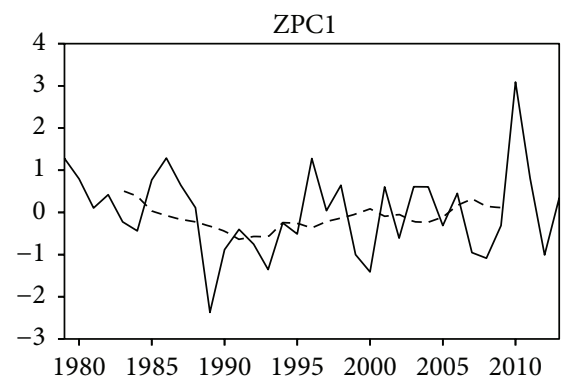

(d)

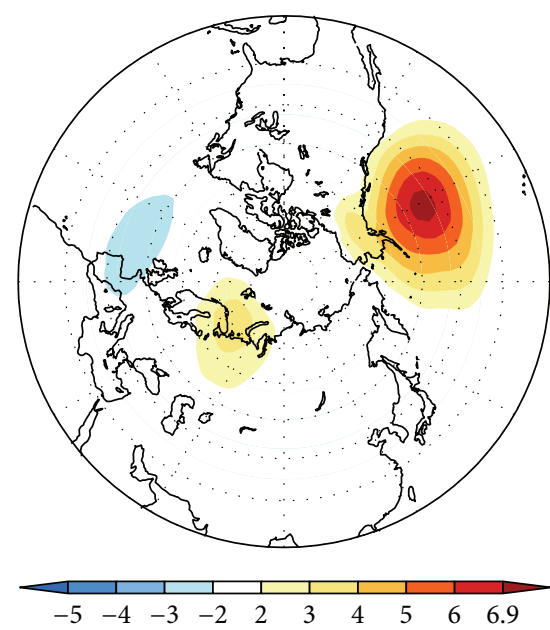

(b)

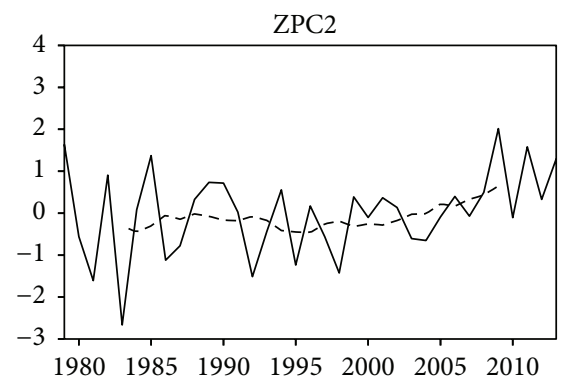

(e)

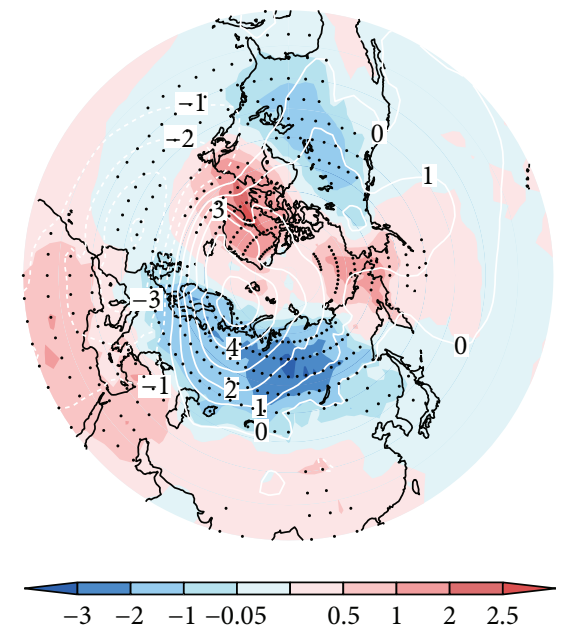

(c)

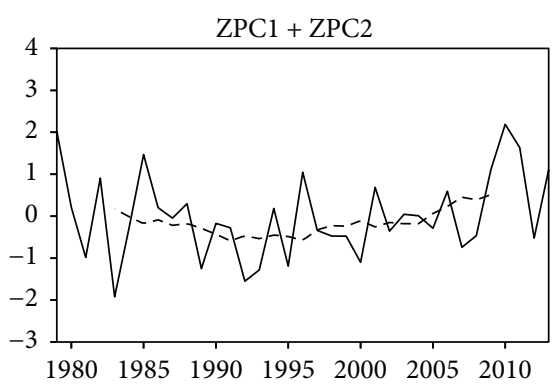

(f)

FIGURE 10: The spatial distribution of the first two leading modes of the extratropical Z1000 in the Northern Hemisphere and their associated circulation anomalies. (a, d) are for EOF1 and its corresponding $\mathrm{ZPC1}$ and (b, e) are EOF2 and ZPC2, respectively. The units are gpm for Z1000 in (a, d). (c) The regression coefficients of SAT and Z1000 in relation to ZPC1 + ZPC2. (f) The units are gpm for Z1000 and K for SAT. Dashed lines in (d, e, f) denote the corresponding 9-yr running mean for the original time series (solid line). The dotted areas in (c) indicate significantly regressed SAT exceeding 0.05 for the $F$-test.

We further constructed a multivariate linear regression time series (ZPC1 + ZPC2) by jointly regressing ZPC1 and ZPC2 onto ECI. The correlation between ZPC1 + ZPC2 with ECI is 0.55 , which is clearly higher than the individual PCs with ECI. The regression of Z1000 onto ZPC1 + ZPC2 displays striking anticyclonic anomalies in NWEAS, leading to pronounced negative SAT anomalies in the mid-high latitudes of Eurasia. This pattern is identical to the ECI-associated surface circulation anomalies in Figure 8, suggesting that the severe winters in midlatitudinal Eurasia can be explained by a combination of these two extratropical leading modes, particularly in recent decades.

\section{Conclusion and Discussion}

In this study, we defined a new objective index to quantify the intensity of winter coldness (CI) based on the amplitude of daily cold temperature anomalies. The relationship between the change in the CI with the recent frequent low temperature extremes in the midlatitudes of Eurasia (MEA), the associated circulation patterns, and the possible contributing factors was analyzed. Our major results are summarized as follows.
(1) The change in the CI in MEA is highly consistent with the recent intensified low temperature extremes. However, the subseasonal variance of temperature at $45^{\circ} \mathrm{N}-60^{\circ} \mathrm{N}$ of MEA shows a decreased trend with -1.0 per decade that is inconsistent with increase of cold extremes in the recent decades. The dominant mode of the CI in MEA features a sign-consistent variation with a marked intensification since 2005 according to empirical orthogonal function (EOF) analysis. This leading mode is significantly related to the frequency of extreme cold days (nights) in winter over large areas of the mid-high latitudes of Eurasia. Therefore, a regional integrated index ECI is defined to quantify the overall intensity of winter coldness in MEA, which is highly correlated with $\mathrm{PC1}$.

(2) The differences in the SLP between high and low ECI values are characterized by a remarkable anomalous anticyclone in northwestern Eurasia. This blocking-like circulation dynamically weakens the warm-wet air from the North Atlantic to west of Europe and transports cold, dense air from the high latitudes to Siberia and East Asia; thus, substantial cold advection is induced across MEA. 
(3) We found that the large-scale strengthening and increasing of synoptic weather systems, including surface Eurasian anticyclones and synoptic blocking over $25^{\circ} \mathrm{E}-85^{\circ} \mathrm{E}$, substantially corresponds to the widespread intensification of the CI in MEA. Additionally, the frequent severe winters are also likely coupled with a positive phase shift of the first two extratropical circulation leading modes, which feature a similar blocking-like anomaly in the northwestern Eurasian subarctic.

There are several other issues related to winter Eurasian coldness that need to be studied in the future. The detailed dynamical coupled processes influencing synoptic weather systems and the stationary extratropical leading mode of winter temperature extremes across MEA are unknown. Furthermore, external forcing deserves further investigation based on observations and simulations. In Section 3.4, we show a higher correlation with ECI using multivariate regressed $\mathrm{ZPC1}$ and $\mathrm{ZPC} 2$. Since the $\mathrm{ZPC1}$ is closely linked to the $\mathrm{AO}$, this suggests there are other independent potential driven factors linked with the recent Eurasian cold winters. Mori et al. [14] argued that the atmospheric response to sea-ice decline is approximately independent of the Arctic Oscillation. The atmospheric response to both the Arctic Oscillation and sea-ice decline favors cold-air advection to Eurasia and hence severe winters. Li et al. [31] also argued that Arctic sea-ice loss does not drive systematic changes in the Northern Hemisphere large-scale circulation in the past decades but enhances the variability of Eurasian winter climate and thus increases the probability of an extreme Eurasian winter cooling trend. Therefore, the recent severer cold winter in Eurasia may be due to the jointly influence of atmospheric internal variability (e.g., $\mathrm{AO} / \mathrm{NAO}$ ) and external forcing (e.g., Arctic sea-ice decline [32] and snow cover [33]). More data analysis and high-resolution model simulations and projections will be pursued in the future.

\section{Competing Interests}

The authors declare that there is no competing interests regarding the publication of this paper.

\section{Acknowledgments}

This work is supported jointly by the National Basic Research Program of China (2015CB953904), the Natural Science Foundation of Jiangsu Province grant (BK2012465), the National Natural Science Foundation of China (41575081, 41575057), and a project funded by the Priority Academic Program Development of Jiangsu Higher Education Institutions (PAPD).

\section{References}

[1] X. Zhang, A. Sorteberg, J. Zhang, R. Gerdes, and J. C. Comiso, "Recent radical shifts of atmospheric circulations and rapid changes in Arctic climate system," Geophysical Research Letters, vol. 35, no. 22, Article ID L22701, 2008.

[2] J. E. Overland, "Potential Arctic change through climate amplification processes," Oceanography, vol. 24, no. 3, pp. 176-185, 2011.
[3] B. Y. Wu, J. Z. Su, and R. H. Zhang, "Effects of autumn-winter Arctic sea ice on winter Siberian High," Chinese Science Bulletin, vol. 56, no. 30, pp. 3220-3228, 2011.

[4] L. Wang and W. Chen, "Downward Arctic Oscillation signal associated with moderate weak stratospheric polar vortex and the cold December 2009," Geophysical Research Letters, vol. 37, no. 9, Article ID L09707, 2010.

[5] M. Wen, S. Yang, A. Kumar, and P. Zhang, "An analysis of the large-scale climate anomalies associated with the snowstorms affecting China in January 2008," Monthly Weather Review, vol. 137, no. 3, pp. 1111-1131, 2009.

[6] C. Bueh, N. Shi, and Z. Xie, "Large-scale circulation anomalies associated with persistent low temperature over Southern China in January 2008," Atmospheric Science Letters, vol. 12, no. 3, pp. 273-280, 2011.

[7] V. Petoukhov and V. A. Semenov, "A link between reduced Barents-Kara sea ice and cold winter extremes over northern continents," Journal of Geophysical Research, vol. 115, no. 21, Article ID D21111, 2010.

[8] J. A. Francis and S. J. Vavrus, "Evidence linking Arctic amplification to extreme weather in mid-latitudes," Geophysical Research Letters, vol. 39, no. 6, Article ID L06801, 2012.

[9] J. Liu, J. A. Curry, H. Wang, M. Song, and R. M. Horton, "Impact of declining Arctic sea ice on winter snowfall," Proceedings of the National Academy of Sciences of the United States of America, vol. 109, no. 11, pp. 4074-4079, 2012.

[10] E. A. Barnes, "Revisiting the evidence linking Arctic amplification to extreme weather in midlatitudes," Geophysical Research Letters, vol. 40, no. 17, pp. 4734-4739, 2013.

[11] J. A. Screen and I. Simmonds, "Caution needed when linking weather extremes to amplified planetary waves," Proceedings of the National Academy of Sciences of the United States of America, vol. 110, no. 26, p. E2327, 2013.

[12] P. Hassanzadeh, Z. Kuang, and B. F. Farrell, "Responses of midlatitude blocks and wave amplitude to changes in the meridional temperature gradient in an idealized dry GCM," Geophysical Research Letters, vol. 41, no. 14, pp. 5223-5232, 2014.

[13] Z. Han, S. Li, and M. Mu, "The role of warm North Atlantic SST in the formation of positive height anomalies over the Ural Mountains during January 2008," Advances in Atmospheric Sciences, vol. 28, no. 2, pp. 246-256, 2011.

[14] M. Mori, M. Watanabe, H. Shiogama, J. Inoue, and M. Kimoto, "Robust Arctic sea-ice influence on the frequent Eurasian cold winters in past decades," Nature Geoscience, vol. 7, pp. 869-873, 2014.

[15] Y. Peings and G. Magnusdottir, "Forcing of the wintertime atmospheric circulation by the multidecadal fluctuations of the North Atlantic ocean," Environmental Research Letters, vol. 9, no. 3, Article ID 034018, 2014.

[16] S. Chen, W. Chen, and K. Wei, "Recent trends in winter temperature extremes in eastern China and their relationship with the Arctic Oscillation and ENSO," Advances in Atmospheric Sciences, vol. 30, no. 6, pp. 1712-1724, 2013.

[17] W. Zhou, J. C. L. Chan, W. Chen, J. Ling, J. G. Pinto, and Y. Shao, "Synoptic-scale controls of persistent low temperature and icy weather over Southern China in January 2008," Monthly Weather Review, vol. 137, no. 11, pp. 3978-3991, 2009.

[18] J. Inoue, M. E. Hori, and K. Takaya, "The role of barents sea ice in the wintertime cyclone track and emergence of a warmArctic cold-Siberian anomaly," Journal of Climate, vol. 25, no. 7, pp. 2561-2569, 2012. 
[19] Y. J. Orsolini, R. Senan, R. E. Benestad, and A. Melsom, "Autumn atmospheric response to the 2007 low Arctic sea ice extent in coupled ocean-atmosphere hindcasts," Climate Dynamics, vol. 38, no. 11-12, pp. 2437-2448, 2012.

[20] X. Zhang, C. Lu, and Z. Guan, "Weakened cyclones, intensified anticyclones and recent extreme cold winter weather events in Eurasia," Environmental Research Letters, vol. 7, no. 4, Article ID 044044, 2012.

[21] D. Gong, S. Wang, and J. Zhu, "Arctic Oscillation influence on daily temperature variance in winter over China," Chinese Science Bulletin, vol. 49, no. 6, pp. 637-642, 2004.

[22] Y. Xie, Y. Liu, and J. Huang, "The influence of the autumn Arctic sea ice on winter air temperature in China," Acta Meteorologica Sinica, vol. 72, no. 4, pp. 703-710, 2014 (Chinese).

[23] J. A. Screen, "Arctic amplification decreases temperature variance in northern mid- to high-latitudes," Nature Climate Change, vol. 4, no. 7, pp. 577-582, 2014.

[24] T. Schneider, T. Bischoff, and H. Płotka, "Physics of changes in synoptic midlatitude temperature variability," Journal of Climate, vol. 28, no. 6, pp. 2312-2331, 2015.

[25] D. P. Dee, S. M. Uppala, A. J. Simmons et al., “The ERA-Interim reanalysis: configuration and performance of the data assimilation system," Quarterly Journal of the Royal Meteorological Society, vol. 137, no. 656, pp. 553-597, 2011.

[26] G. R. North, T. L. Bell, R. F. Cahalan, and F. J. Moeng, "Sampling errors in the estimation of empirical orthogonal functions," Monthly Weather Review, vol. 110, no. 7, pp. 699-706, 1982.

[27] X. Zhang, E. Aguilar, S. Sensoy et al., "Trends in Middle East climate extreme indices from 1950 to 2003," Journal of Geophysical Research D: Atmospheres, vol.110, no. 22, Article ID D22104, 2005.

[28] Y. Ding and T. N. Krishnamurti, "Heat budget of the Siberian high and the winter monsoon," Monthly Weather Review, vol. 115, no. 10, pp. 2428-2449, 1987.

[29] J. G. Charney, J. Shukla, and K. C. Mo, "Comparison of a barotropic blocking theory with observation," Journal of the Atmospheric Sciences, vol. 38, no. 4, pp. 762-779, 1981.

[30] K. Guirguis, A. Gershunov, R. Schwartz, and S. Bennett, "Recent warm and cold daily winter temperature extremes in the Northern Hemisphere," Geophysical Research Letters, vol. 38, no. 17, Article ID L1770, 2011.

[31] C. Li, B. Stevens, and J. Marotzke, "Eurasian winter cooling in the warming hiatus of 1998-2012," Geophysical Research Letters, vol. 42, no. 19, pp. 8131-8139, 2015.

[32] Z. Guan, Q. Zhang, and M. Li, "Interannual variations in atmospheric mass over liquid water oceans, continents, and sea-icecovered arctic regions and their possible impacts on the boreal winter climate," Journal of Geophysical Research: Atmospheres, vol. 120, no. 23, pp. 11,846-11,861, 2015.

[33] J. L. Cohen, J. C. Furtado, M. A. Barlow, V. A. Alexeev, and J. E. Cherry, "Arctic warming, increasing snow cover and widespread boreal winter cooling," Environmental Research Letters, vol. 7, no. 1, Article ID 014007, 2012. 

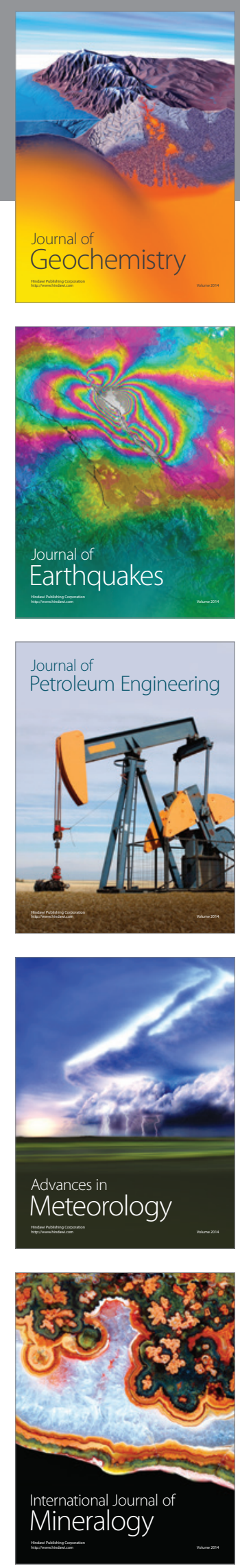
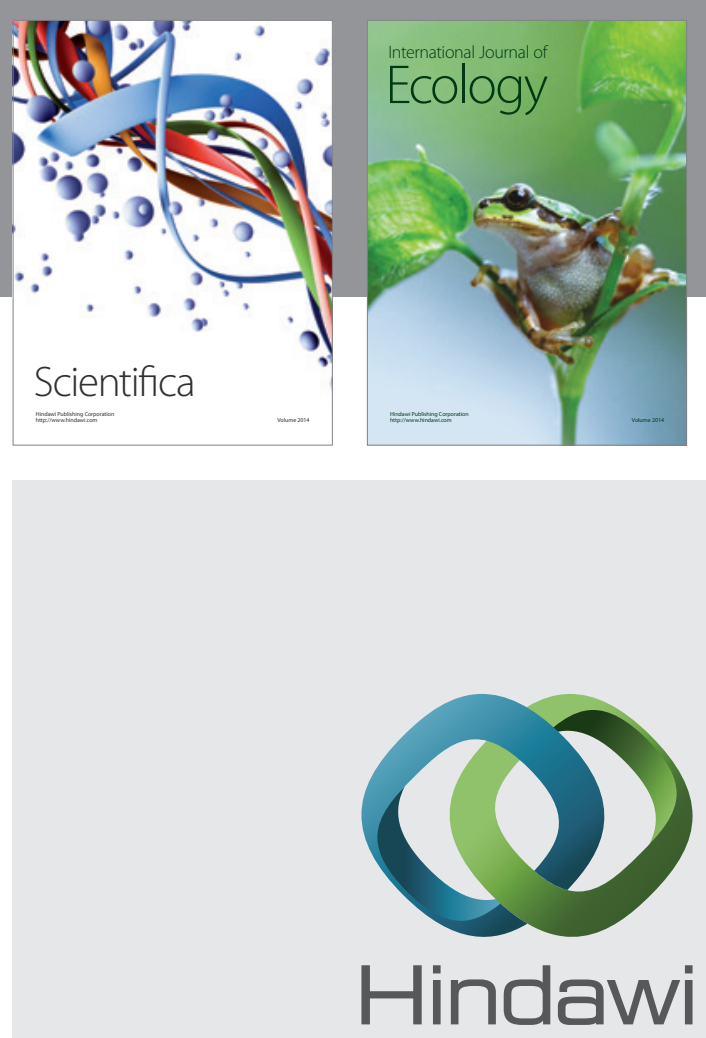

Submit your manuscripts at

http://www.hindawi.com
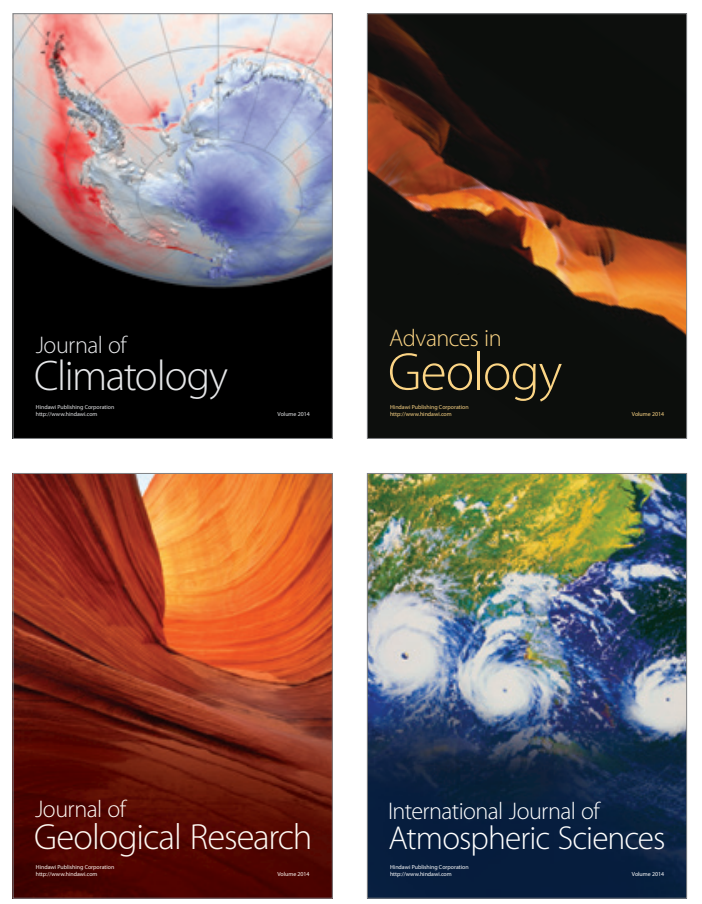

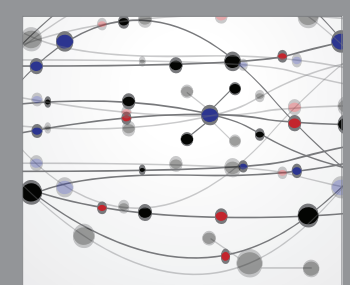

The Scientific

\section{World Journal}
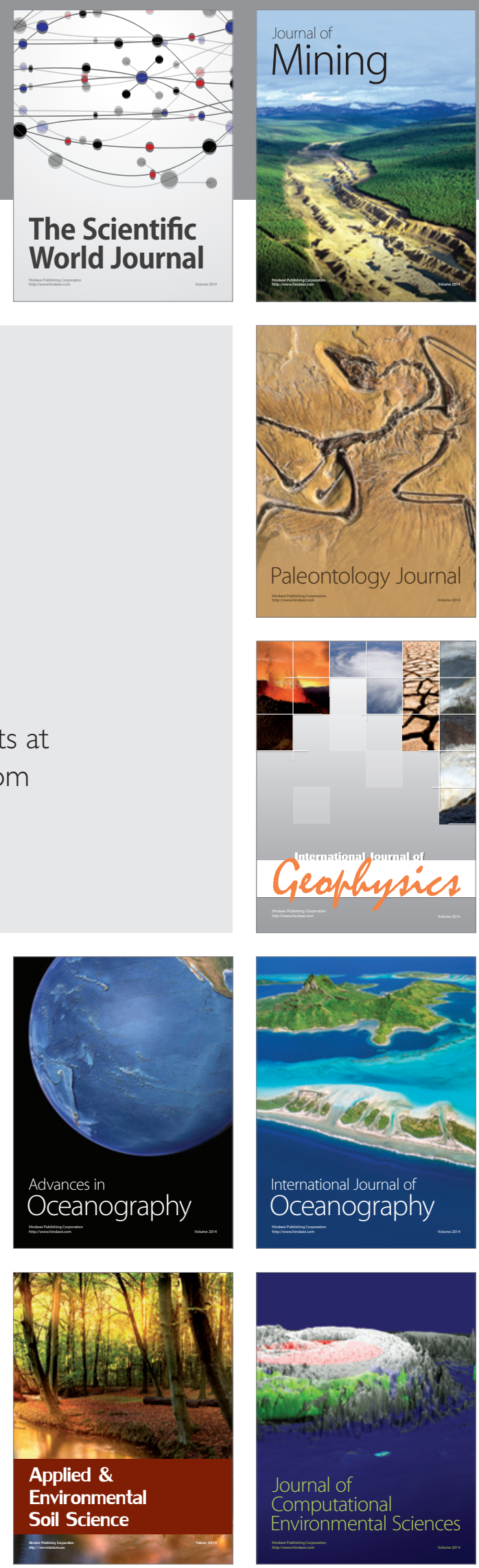